\title{
Cervical foraminal steroids infiltration using ultrasonographic technique for the treatment of cervical radiculalgia: $A$ retrospective study
}

\author{
Schrepel S. ${ }^{1}$, MD; Bali M. A. ${ }^{1}$, MD; Kapessidou P. ${ }^{1}$, MD, PhD. \\ ${ }^{1}$ Department of Anesthesiology and Pain Medicine, Saint-Pierre University Hospital, Université Libre de Bruxelles (ULB), Brussels, \\ Belgium.
}

\section{Introduction and Aim}

Cervical Foraminal Steroids Infiltration (CFSI) is indicated in cervico-brachial radicular pain, resistant to conservative treatment. It was performed under fluoroscopic or tomodensitometric's control, with beneficial reported effects ${ }^{1}$. However, severe neurological complications following radioguided injections have been reported ${ }^{2}$.

Studies demonstrating the effectiveness and safety of CFSI using ultrasonographic technique are limited ${ }^{3,4}$. The primary endpoint of this retrospective study was to evaluate the efficacy of CFSI performed under ultrasonography. We secondarily assessed the associated complications of the technique.

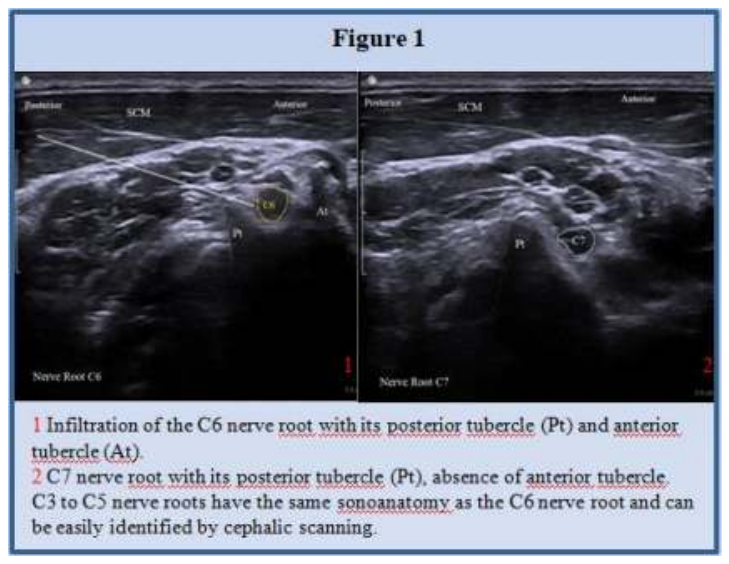

Materials and Methods also in diabetic's patients.

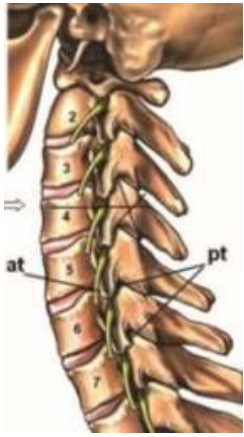

Gofeld et al. (2008)

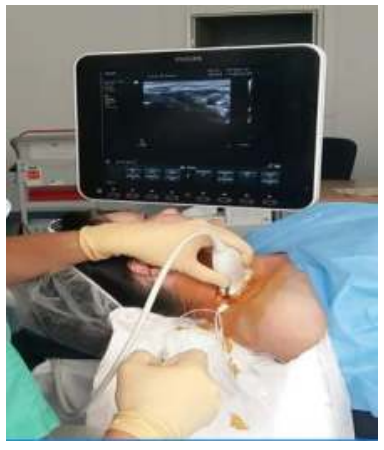

After ethic committee approval (O.M. 007), 194 patients were included in this retrospective study, between January 2016 and October 2017, based on diagnosis and treatment for CFSI. A DN4 questionnary score was made in the consultation before the infiltration in order to detect neuropathic pain. Identification of the predefined target level (depending on cervical vertebrae anatomy) and the foramen was performed under ultrasound guidance (Figure 1). Infiltration was realised after adequate needle position. Efficacy was defined by visual analog score (VAS) assessment, before and one month after CFSI in DN4 positive and negative group,

Percentage of symptom's improvement, (reflection of quality of life) need for surgery after infiltration, modification of oral treatment was also reported. Safety was investigated with early or late complications. Statistical analysis was realized by T-test, Wilcoxon and Pearson's $\mathrm{Chi}^{2}$. Data are presented as mean values \pm standard deviation $(\mathrm{SD}), \mathrm{p}<0.05$ was considered significant.

\section{Results}

Echoguided CFSI were found efficient reducing VAS in DN4 negative (6 [5 - 8] to $0[0-3])$ and DN4 positive patients (7 [6 - 8] to 0 [0 - 3], p:0.948) (table 1). Diabetics patients response to treatment was not significantly different $(p=0,153)$. No improvement of symptoms (table 2) was observed in $6.7 \%$ of DN4 negative patient and $8,93 \%$ in DN4 positive patient, there was no statistical difference between the two groups. $100 \%$ of improvement was observed in $60 \%$ of DN4 negative patient and $64,8 \%$ of DN4 positive patient, with no statistical difference. 2 patients $(13,3 \%)$ in DN4 negative and 3 patients $(3,93 \%)$ in DN4 positive groupe have needeed for cervical surgery. $6.7 \%$ of patients showed early complications such as dizziness, vagal discomfort, and one intravascular injection. No late complications were observed.

Table 2- Percentage of symptom improvement, by group

\begin{tabular}{llll}
\hline \% Improvement & Negative DN4 score (n=15) & Positive DN4 score (n=179) & P-value \\
\hline $\mathbf{0} \%$ & $1 / 15(6.67 \%)$ & $16 / 179(8.93 \%)$ & 0.9069 \\
$<\mathbf{5 0} \%$ & $1 / 15(6.67 \%)$ & $13 / 179(7.26 \%)$ & \\
$\mathbf{5 0 - 9 9} \%$ & $415(26.67 \%)$ & $34 / 179(18.99 \%)$ & \\
$\mathbf{1 0 0} \%$ & $9 / 15(60 \%)$ & $116 / 179(64.80 \%)$ & \\
\hline
\end{tabular}

\begin{tabular}{|l|l|l|l|}
\hline \multicolumn{4}{|c|}{ Table 1- Visual analog score variations, by group } \\
\hline & $\begin{array}{l}\text { Negative DN4 } \\
\text { score }(n=15)\end{array}$ & $\begin{array}{l}\text { Positive DN4 } \\
\text { score }(n=179)\end{array}$ & P-value \\
\hline $\begin{array}{l}\text { VAS before } \\
\text { CFSI }\end{array}$ & $6[5-8]$ & $7[6-8]$ & 0.52 \\
\hline $\begin{array}{l}\text { VAS after } \\
\text { CFSI }\end{array}$ & $0[0-3]$ & $0[0-3]$ & 0.95 \\
\hline VAS reduction & $4[3-6]$ & $5[3-7]$ & 0.48 \\
\hline & $\begin{array}{l}\text { No diabetes } \\
(n=171)\end{array}$ & Diabetes $(n=29)$ & P-value \\
\hline $\begin{array}{l}\text { VAS before } \\
\text { CFSI }\end{array}$ & $7[6-8]$ & $7[5-8]$ & 0.9345 \\
\hline VAS after CFSI & $0[0-3.5]$ & $0[0-2.25]$ & 0.3082 \\
\hline VAS reduction & $5[3-7]$ & $6[3-7]$ & 0.1537 \\
\hline
\end{tabular}

\section{Conclusions}

CFSI using ultrasound seems to be an efficient and safe technique under the conditions of this study. It may be beneficial also for patients with DN4 negative score and diabetes.

References: ${ }^{1}$ Engel, A. Pain Med 2014; 15:386-402, ${ }^{2}$ Morelet A. Revue du Rhumatisme 2006; 73:1108

${ }^{3}$ Galiano K. J Ultrasound Med. 2005; 24:33-38, ${ }^{4}$ Narouze, S. Regional Anesthesia and Pain Medicine 2009; 34:343-348.

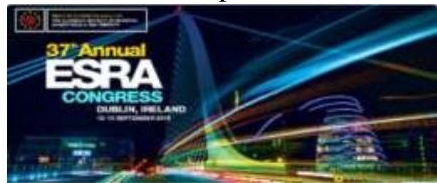

